\title{
Polycystic ovary syndrome and its relevance to women from south Asia
}

\author{
The syndrome has vast epidemiological, socio-economic and health care delivery implications for \\ south Asia
}

\section{Introduction}

Polycystic ovary syndrome (PCOS) is the commonest endocrine disturbance in women of reproductive years, and its aetiology remains unclear (1). Its clinical features include hyperandrogenism, obesity, menstrual irregularity and anovular infertility, but the clinical presentation can vary. PCOS in the commonest cause of anovulatory infertility and hirsutism world-wide (2). PCOS is associated with insulin resistance and hyperinsulinaemia, with a risk of glucose intolerance (3). A wide range of biochemical abnormalities occurs in PCOS (4) that form the basis of its clinical features and associated disease risks (Table 1). PCOS is familial and thought to be the morphological manifestation of a genetically determined disorder, whereas its heterogeneity is believed to result from interaction with environmental factors (2).

Defining the polycystic ovary (PCO) and polycystic ovary syndrome

The diagnosis of $\mathrm{PCO}$, based on transvaginal ultrasound, requires the presence of 15 cysts of 2 to $10 \mathrm{~mm}$ diameter arranged in a single plane (5). The presence of polycystic ovaries alone does not diagnose the endocrine syndrome. PCOS lacks a universal definition. Other causes of hyperandrogenism manifest similarly, eg. late onset congenital adrenal hyperplasia (CAH), and syndromes of extreme insulin resistance (eg. leprechaunism, RabsonMendenhall syndrome, Type A syndrome) $(3,4)$. In the USA the diagnosis of PCOS requires the presence of hyperandrogenism, hyperandrogenaemia, oligo-ovulation regardless of ovarian scan appearance, and the exclusion of $\mathrm{CAH}$, hyperprolactinaemia and Cushing's syndrome $(1,6,7)$. In Europe its diagnosis is based on ultrasound evidence of PCO, combined with one or more associated clinical or biochemical characteristics, in the absence of adrenal or pituitary disease $(1,8,9,10)$.

\section{The role of insulin resistance in PCOS \\ Ovarian hyperandrogenism}

All women with $\mathrm{PCO}$, including the asymptomatic, have elevated serum androstenedione and testosterone. The bulk of evidence points to the ovary being their source. The theca cells in PCOS hyper-respond to luteinising hormone ( $\mathrm{LH}$ ) and produce excess androgens, caused partly by altered cytochrome P450c17 action in steroidogenesis, and partly by altered ovarian insulin and insulin like growth factor 1 (IGF 1) activity (11). Increased levels of oestradiol result from peripheral aromatisation of excess androgens, and from follicle stimulating hormone (FSH) induced ovarian follicular secretion. Plasma inhibinB is elevated in women with PCOS; inhibin stimulating androgen production and androgens in turn stimulating

Table 1. Biochemical abnormalities, associated clinical features, complications and risks in PCOS

\section{Biochemical derangement}

High testosterone/ androstenedione Decreased sex hormone binding globulin

Acyclic oestrogen excess

Insulin resistance and hyperinsulinaemia

\section{Associated clinical features}

Hirsutism

Frontal balding

Acne

Hydradenitis suppurativa
Resulting complications

Anovular infertility
Risk stratification

Increased risk Menstrual irregularity/
oligomenorrhoea

Acanthosis nigricans Obesity

\author{
Endometrial cancer \\ Ovarian cancer \\ Breast cancer \\ Diabetes mellitus \\ Gestational diabetes \\ Hypertension \\ Pregnancy induced \\ hypertension
}

Increased risk Probable risk Remote risk

Increased risk Increased risk Probable risk Probable risk 
inhibin secretion, thus establishing a vicious circle within the ovary that inhibits ovulation. Although ovarian follicle recruitment and growth remain unaffected, the selection of a dominant preovulatory follicle does not occur in PCOS (11). In summary, ovarian insulin, IGFI and inhibin act on the LH driven theca cell to produce excess androgens by altered cytochrome activity, and the androgens in turn with insulin and IGFI, act on the FSH driven granulosa cell causing anovulation and increased oestrogens.

\section{Insulin resistance, obesity and $P C O S$}

PCOS is perhaps the commonest disorder in which an association between insulin resistance and altered ovarian function are improtant $(3,12)$. Insulin acts on the normal ovary by a receptor mediated stimulation of steroidogenesis. Ovarian effects of increased insulin are described in women with diabetes mellitus, obesity, syndromes of extreme insulin resistance and PCOS (12). The efficacy of insulin sensitising agents such as metformin in the treatment of PCOS supports this hypothesis (13). Women with PCOS have peripheral insulin resistance affecting skeletal muscle and adipose tissue, although insulin resistance does not effect the ovary, thus enabling the excess insulin to cause ovarian androgen hypersecretion $(12,14)$. Obese women with PCOS are more insulin resistant than nonobese controls, suggesting that obesity and PCOS exert independent effects on insulin resistance. But weight loss restores insulin sensitivity only in some, and insulin resistance is described also in non-obese PCOS subjects (12). Insulin resistance in PCOS is more prominent in anovular women than equally hyperandrogenaemic women with regular menses $(3,14)$. In vitro studies of insulin action on granulosa cells from PCO show that hyperinsulinaemia causes premature arrest of follicular growth and amplifies thecal androgen production (15). Obese and non-obese women with PCOS have exaggerated insulin secretion following a glucose load that is inadequate relative to their degree of insulin resistance (16). Women with PCOS have "android obesity", with fat deposition confined to the upper two-thirds of the body, and a waist-hip ratio exceding 0.85 . Increased waist-hip ratio occurs independent of body mass index, and correlates with dyslipidaemia and insulin resistance (17).

\section{Birth weight, PCOS, and their link to adult type 2 diabetes}

The existence of specific prenatal risks for the postpubertal expression of PCOS remains under scrutiny. The relationship between intrauterine growth retardation and adult insulin resistance and glucose intolerance is well established (18). Polycystic ovaries may reflect fetal programming, for a retrospective analysis reported that obese, hirsute, hyperandrogenic women with PCO were bom large for gestational age (19).

\section{Natural progression of PCOS}

The onset of symptoms of PCOS is linked to menarche, and puberty is accompanied by a physiological insulin resistance (20). Menstrual disturbance is the earliest manifestation, and hirsutism and infertility become apparent later. The evolution of symptoms with age appears to be associated with increase of adiposity (21). Androgen excess occurs in more than $70 \%$ of those affected, infertility results from anovulation, and excess $\mathrm{LH}$ is associated with a high rate of miscarriage in PCOS (21).

\section{Genetics of PCOS and the link to type 2 diabetes}

Family studies of PCOS There is a high incidence of $P C O S$ in first degree relatives of the affected, and most studies suggest a dominant inheritance (22-28). All studies reported so far have been of families of white European descent, with none from those of south Asian descent (Table 2).

Male phenotype Many male phenotypes have been proposed (Table 2) $(22-26,28)$. Increased prevalence of frontal baldness in male relatives was first reported in 1979 (24), to which hyperinsulinaemia was later included (28).

Twin studies in PCOS The only large study in twins revealed an incidence of $50 \%$ for PCO in monozygotic and dizygotic twins, but with strong discordance. These data suggest a complex inheritance pattern, perhaps polygenic, which is linked to insulin resistance (29).

Affected sisters with PCOS On average, the occurrence of hirsutism and oligomenorrhoea among sisters of the proband is about $50 \%(22,24,25,28)$, of PCO $73 \%$, or hyperandrogenaemia $87 \%$ and of hyperinsulinaemia $66 \%(7,28)$. A recent report of a large number of sisters of affected women showed that $22 \%$ of sisters had well characterised PCOS, and another $24 \%$ had hyperandrogenaemia with regular cycles (7). Several phenotypes of PCOS are reported to occur within a given family, which supports a heterogeneous genetic basis with variable expression of a monogenic trait or an oligogenic trait $(7,30)$.

Molecular genetic studies in PCOS Making no assumption of the mode of inheritance, a search was carried out for candidate genes in the androgen biosynthetic pathway, and in the secretion and action of insulin (30). The genetic association and linkage with PCOS reported so far include: a) the CYPlla gene, which converts cholesterol to pregnenolone, a rate-limiting step in androgen biosynthesis (31); b) insulin gene variable number of tandem repeats (VNTR) polymorphism, particularly class I and III alleles, linked to an increased susceptibility to type 2 diabetes and high birth weight (32); c) a microsatellite located outside the insulin receptor (INSR) gene possibly influencing INSR gene expression in the ovary (33); d) follistatin gene (which has not been substantiated by other workers) (34), and e) Accl polymorphism in the FSH $\beta$ gene (35). All these studies were predominantly on women of white European descent, except for the FSH $\beta$ gene tested in affected south Asians and Chinese women resident in Singapore. 
Table 2. Review of family studies in PCOS and proposed male phenotypes and modes of inheritance

\begin{tabular}{|c|c|c|c|c|}
\hline $\begin{array}{l}\text { Reference } \\
\text { number }\end{array}$ & $\begin{array}{l}\text { Phenotypic criteria } \\
\text { of } P C O S\end{array}$ & Sample characteristics & $\begin{array}{l}\text { Proposed male } \\
\text { phenotype }\end{array}$ & $\begin{array}{l}\text { Proposed mode } \\
\text { of inheritance }\end{array}$ \\
\hline 22 & $\begin{array}{l}\text { Menstrual irregularity } \\
\text { Hirsutism } \\
\text { PCO (by culdoscopy) }\end{array}$ & $\begin{array}{l}\text { Small cohort of PCOS } \\
\text { First degree relatives }+ \\
\text { Control group } t\end{array}$ & Increased pilosity & $A D$ \\
\hline 23. & $\begin{array}{l}\text { Menstrual irregularity } \\
\text { Hirsutism } \\
\text { PCO (by surgery) }\end{array}$ & $\begin{array}{l}\text { Few kindreds of } \\
\text { several generations }\end{array}$ & $\begin{array}{l}\text { Testicular } \\
\text { dysfunction }\end{array}$ & $\begin{array}{l}\text { ? X-linked } \\
\text { dominant }\end{array}$ \\
\hline 24 & $\begin{array}{l}\text { Menstrual irregularity } \\
\text { PCO (by gynaecography) }\end{array}$ & $\begin{array}{l}\text { Large cohort of PCOS, } \\
\text { First/second degree } \\
\text { relatives }+ \\
\text { Controls }+\end{array}$ & Premature balding & Dominant \\
\hline 25 & $\begin{array}{l}\text { Symptoms of PCOS } \\
\text { PCO (at wedge resection) }\end{array}$ & $\begin{array}{l}\text { Large cohort of PCOS, } \\
\text { First/second degree } \\
\text { relatives + } \\
\text { Controls + }\end{array}$ & $\begin{array}{l}\text { Increased pilosity } \\
\text { Premature balding }\end{array}$ & ?AD \\
\hline 26 & $\begin{array}{l}\text { Symptoms of PCOS } \\
\text { PCO (by ultrasound) }\end{array}$ & $\begin{array}{l}\text { PCOS cohort } \\
\text { CAH cohort }+ \\
\text { Controls }+\end{array}$ & - & $\mathrm{AD}$ \\
\hline 27 & PCO (by ultrasound) & Several kindreds & Premature balding & $\mathrm{AD}$ \\
\hline 28 & $\begin{array}{l}\text { Elevated androgens } \\
\text { Decreased SHBG } \\
\text { PCO by ultrasound }\end{array}$ & Few kindreds & Insulin resistance & Not stated \\
\hline
\end{tabular}

( $\mathrm{PCO}=$ polycystic ovaries; $\mathrm{PCOS}=$ polycystic ovary syndrome; $\mathrm{CAH}=$ congenital adrenal hyperplasia; $\mathrm{AD}=$ autosomal dominant)

\section{Epidemiology of PCOS and its relevance to south Asian women}

The prevalence of PCOS is variable due to lack of a universal definition (36). Population studies of randomly selected normal white European women of reproductive age report the prevalence of PCO to be 20 to $22 \%$ (9), and $33 \%$ in the post-menarcheal group (10). Using the USA criteria, the prevalence of PCOS in population based studies was $5 \%$ to $11.2 \%$ in Alabama (37), 9\% in Greece (38) and $6.5 \%$ in Spain (39). The highest reported prevalence of $\mathrm{PCO}$ in a community survey was $52 \%$ in south Asian immigrants in Britain, of whom $49 \%$ had menstrual irregularity (40). There is a paucity of data on the prevalence of PCO and PCOS in south Asian women.

Ethnic differences in the prevalence of PCOS have not been explored (36). An increased rate of PCOS was reported among Caribbean Hispanics (41), but is similar between black and white women (3.4\% versus $4.7 \%$ ) (37). There may be ethnic variation in overt features of PCOS despite similar biochemical manifestations across races, since affected Japanese women are less obese and hirsute than Caucasians although with similar androgen excess and insulin resistance (42).
Epidemiology of type 2 diabetes mellitus in south Asian women and its implications on PCOS

Type 2 diabetes mellitus shows strong familial aggregation in populations with insulin resistance (43). The south Asian subcontinent has a high prevalence of type 2 diabetes, with central obesity strongly associated with diabetes in women (44). The prevalence of diabetes in urban and rural women in Pakistan is reported to be $10.6 \%$ and $4.8 \%$ respectively, and of impaired glucose tolerance $14.3 \%$ and $13 \%$, values higher than in Caucasians (45). Similar trends in both genders are reported from India (46), and Sri Lanka (47). The largest projected number of diabetics by year 2025 is in India (57 million), among younger age groups and greater numbers of women (48). The high prevalence in south Asia is in striking contrast to that in white Europeans (49). It is postulated, based on data among Caucasians alone, that PCOS contributes to $10 \%$ of glucose intolerance in premenopausal women (50). Hence the implications of PCOS on diabetes in south Asian women would be of great importance.

Abnormal fetal growth and low birth weight are linked to a higher prevalence of glucose intolerance, hypertension and vascular disease caused by insulin resistance in 
adult life $(18,51)$. Such a "fetal origins" hypothesis proposes that fetal adaptation to an adverse intrauterine environment effects lifelong physiological changes in neuroendocrine development, even affecting the hypothalamopituitary-adrenal axis (52). Low birth weight has a high incidence in south Asia, including Sri Lanka (47,49). Hence such a mechanism of hormonal alteration could link insulin resistance of PCOS with type 2 diabetes in south Asian women. Reports of a high prevalence of type 2 diabetes mellitus in native south Asian women, the highest recorded prevalence of $\mathrm{PCO}$ being in migrant women of south Asian descent, suggest a possible common genetic or fetal origin.

The insulin response to a glucose challenge in a small group of PCOS women of Indian and white European origin based in Australia reported that Indian women have significantly higher insulin response (53), which confirms that the ethnic background of subjects with PCOS needs consideration. A review of the "metabolic syndrome" (which links adult insulin resistance with hypertension, dyslipidaemia, type 2 diabetes and coronary heart disease), confirms the genetic and ethnic influence in its development (54).

To summarise, (a) PCOS in young women, rather than being limited to gynaecological or dermatological problems, has much wider and long term metabolic implications; (b) insulin resistance is central to its pathogenesis, with a strong genetic basis, and important implications to its management; (c) the majority of research on PCOS has been in those of white European descent, and the only report on the prevalence of PCO in a migrant south Asian population in England has found it to be strikingly higher than in Caucasians; (d) type 2 diabetes, which is preceded by insulin resistance, is an emerging problem in women of indigenous populations in south Asia; and (e) the prevalence of PCOS in native south Asian women needs to be resolved by large epidemiological studies, and the degree of insulin resistance in affected south Asians also needs quantification.

\section{References}

1. Balen A. Pathogenesis of polycystic ovary syndrome - the enigma unravels? Lancet 1999; 354: 966-77.

2. Franks S. Polycystic ovary syndrome New England Journal of Medicine 1995; 333: 853-61.

3. Dunaif A. Hyperandrogenic anovulation (PCOS): A unique disorder of insulin action associated with an increased risk of non-insulin dependent diabetes mellitus American Journal Medicine (Suppl IA) 1995; 98: 1A-33A.

4. Goudas VT, Dumesic DA. Polycystic ovary syndrome. Endocrinology and Metabolism Clinics of North America 1997; 26: 893-912.

5. Kyei-Mensah A, Maconochie N, Zaidi J, Pittrof R, Campbell S, Tan SL. Transvaginal three-dimensional ultrasound: reproducibility of ovarian and endometrial volume measurements. Fertility Sterility 1996; 5: 718-22.

6. Chang RJ. Polycystic ovary syndrome. Boston; Springer Verlag, 1996.
7. Legro RS. Polycystic ovary syndrome, phenotype and genotype. Endocrinology and Metabolism Clinics of North America 1999; 28: 379-96.

8. Balen AH, Conway GS, Kaltas G, Techatrasak K, Manning PJ, West C, Jacobs HS. Polycystic ovary syndrome: the spectrum of the disorders in 1741 patients. Human Reproduction 1995; 10: 2107-11.

9. Clayton RN, Hogkinson J, Worswick L, Rodin DA, Dyser S. Meade TW. How common are polycystic ovaries in normal women and what is their significance for the fertility of the population? Clinical Endocrinology 1992; 37: 127-34.

10. Michelmore KF, Balen AH, Dunger DB, Vessey MP. Polycystic ovaries and associates; clinical and biochemical features in young women. Clinical Endocrinology 1999; 51: 779-86.

11. Rosenfield RL. Ovarian and adrenal function in polycystic ovary syndrome. Endocrinology and Metabolism Clinics of North America 1999; 28: 265-93.

12. Poretsky L, Cataldo NA, Rosenwaks $Z$ and Guidice $L$. The Insulin-related regulatory system in health and disease. Endocrine Reviews 1999; 20: 535-82.

13. Velezquez EM, Mendoza S, Hamer T, Sosa F, Glueck CJ. Metformin therapy in polycystic ovary syndrome reduces hyperinsulinaemia, insulin resistance, hyperandrogenaemia, and systolic blood pressure, while facilitating normal menses and pregnancy. Metabolism 1994; 43: 647-54.

14. Dunaif A. Insulin resistance and the polycystic ovary syndrome: mechanisms and implications for pathogenesis. Endocrine Reviews 1997; 18: 774-800.

15. Franks $S$, Gilling-Smith $C$, Willis $D$. Insulin action in the normal and polycystic ovary Endocrinology and Metabolism Clinics of North America 1999; 28: 361-378.

16. Holte J, Bergh T, Berne C, Berglund L, Lithell H. Enhanced early insulin response to glucose in relation to insulin resistance in women with polycystic ovary syndrome and normal glucose tolerance. Journal of Clinical Endocrinology and Melabolism 1994; 78: 1052-58.

17. Amowitz LL, Sobel BE. Cardiovascular consequences of polycystic ovary syndrome. Endocrinology and Metabolism Clinics of North America 1999; 28: 439-58.

18. Barker DJP, Hales CN, Fall C, Osmond C, Phipps K, Clark PMS. Type 2 (non-insulin-dependent) diabetes mellitus, hypertension and hyperlipidaemia (syndrome $X$ ): relation to reduced fetal growth. Diabetologia 1993; 36: 62-7.

19. Cresswell JL, Barker DJ, Osmond C, Egger P, Phillips DI, Fraser RB. Fetal growth, length of gestation, and polycystic ovaries in adult life. Lancet 1997; 350: 1131-5.

20. Ibanez L, Potau N, Zampolli M, Street ME, Carrascosa A. Girls diagnosed with premature pubarche show an exaggerated ovarian androgen synthesis from the early stages of puberty: evidence from gonadotrophin hormone agonist lesting. Fertility Sterility 1997; 67: 849-55.

21. Conway GS. Polycystic ovary syndrome: clinical aspects. Bailliere's Clinical Endocrinology and Metabolism 1996; 10: 263-79.

22. Cooper DN, Clayton JF. DNA polymorphism and the study of disease associations. Human Genetics 1988; 78: 299-312.

23. Givens JR. Familial polycystic ovarian disease. Endocrinology and Metabolism Clinics of North America 1988; 17: 771-781.

24. Ferriman D, Purdie AW. The inheritance of polycystic ovarian disease and a possible relationship to premature balding. Clinical Endocrinology 1979; 11: 291-300. 
25. Lunde O, Magnus, P, Sandvik L et al. Familial clustering in the polycystic ovarian disease. Gynaecology and Obstetrics 1989; 28: 23-30.

26. Hague WM, Adams J, Reedres ST et al. Familial polycystic ovaries: a genetic disease? Clinical Endocrinology 1988; 29: 593-605.

27. Carey AH, Chan KL, Short F et al. Evidence for a single gene effect causing polycystic ovaries and male pattern baldness. Clinical Endocrinology 1993; 38: 653-8.

28. Norman RJ, Masters S, Hague W. Hyperinsulinaemia is common if family members of women with polycystic ovary syndrome. Fertility Sterility 1996; 66: 942-7.

29. Jahanfar S, Eden JA, Warren P et al. A twin study of polycystic ovary syndrome. Fertility and Sterility 1995; 63: 478-86.

30. Franks S, Gharani N, Waterworth D, Batty S, White D, Williamson R, McCarthy $M$. The genetic basis of polycystic ovary syndrome. Human Reproduction 1997; 12: 2641-48.

31. Gharani N, Waterworth DM, Batty $S$ et al. Association of the steroid synthesis gene CYPIl a with polycystic ovary syndrome and hyperandrogenism. Human Molecular Genetics 1997; 6: 397-402.

32. Waterworth DM, Bennett ST, Gharani N, McCarthy MI, Hague S, Batty S, et al. Linkage and association of insulin gene VNTR regulatory polymorphism with polycystic ovary syndrome. Lancet 1997; 349: 986-90.

33. Tucci S, Futterweit W, Concepcion ES, Greenberg DA, Villanueva R. et al. Evidence for association of polycystic ovary syndrome in Caucasian women with a marker at the Insulin Receptor Gene Locus. Journal of Clinical Endocrinology and Metabolism 2001, 86: 446-9.

34. Urbanek M, Legro RS, Driscoll DA, Azziz R, Ehrmann DA, et al. Thirty seven candidate genes for polycystic ovary syndrome: Strongest evidence for linkage is with follistatin. Proceedings of the National Academy of Sciences USA 1999; 96: 8573-78.

35. Liao W-X, Tong Y, Roy AC, Ng SC. New Accl polymorphism in the follicle stimulating hormone beta subunit gene and its prevalence in three South East Asian populations. Human Heredity 1999; 49: 181-2.

36. Solomons CG. The epidemiology of polycystic ovary syndrome - prevalence and associated disease risks. Endocrinology and Metabolism Clinics of North America 1999; 28: 247-63.

37. Knochenhauer ES, Key TJ, Kahsar Miller $M$ et al. Prevalence of the polycystic ovary syndrome in unselected black and white women of the Southeastern United States: A prospective study. Journal of Clinical Endocrinology and Metabolism 1998; 83: 3078-82.

38. Diamanti-Kandarakis E, Kouli C, Tsianateli T, et al. A survey of PCOS in Greek population. 79th Annual Meeting of the Endocrine Society, Minneapolis, MN, 1997.
39. Asunction M, Calvo RM, San Millan JL, Sancho J, Avila S, Escoar-Morreale HF. A prospective study of the prevalence of the polycystic ovary syndrome in unselected Caucasian women in Spain. Journal of Clinical Endocrinology and Metabolism 2000; 85: 2434-38.

40. Rodin DA, Bano G, Bland JM, Taylor K, Nussey SS. Polycystic ovaries and associated metabolic abnormalities in Asian women. Clinical Endocrinology 1998; 49: 91-99.

41. Dunaif A, Sorbara L, Delson R et al. Ethnicity and polycystic ovary syndrome are associated with independent and additive decreases in insulin action in Caribbean Hispanic women. Diabetes 1993; 42: 4162-68.

42. Carmina E, Koyama T, Chang L, Stanczyk FZ, Lobo RA. Does ethnicity influence the prevalence of adrenal hyperandrogenism and insulin resistance in polycystic ovary syndrome? American Journal of Obstetrics and Gynaecology 1992; 167: 1807-12.

43. Javanovic L, Gondos B. Type 2 diabetes; the epidemic of the new millennium. Annals of Clinical and Laboratory Science 1999; 29: 33-42.

44. Trevisan $R$, Vedovato $M$, Tiengo $A$. The epidemiology of diabetes mellitus. Nephrology, Dialysis, Transplantation 1998; 13 Suppl 8: 2-5.

45. Shera AS, Rafique G, Khawaja IA, Baqai S, King H. Pakistan national diabetes survey: prevalence of glucose intolerance and associated factors in Baluchisan province. Diabetes Research and Clinical Practice 1999; 44: 49-58.

46. Ramachandran A, Snehalatha C, Latha E, Manoharan M, Vijay $V$. Impacts of urbanization on the lifestyle and on the prevalence of diabetes in native Asian Indian population. Diabetes Research and Clinical Practice 1999; 44: 207-13.

47. Annual Health Bulletin DHS, Ministry of Health, Sri Lanka, 1998.

48. King H, Aubert RE, Herman WH. Global burden of diabetes, 1995-2025: prevalence, numerical estimates, and projections. Diabetes Care 1998; 21: 1414-31

49. World Health Report, 1998.

50. Dunaif A. Insulin action in the polycystic ovary syndrome. Endocrinology and Metabolism Clinics of North America 1999; 28: 341-59.

51. Phillips DI. Birth weight and the future development of diabates. A review of the evidence. Diabetes Care 1998; 21 (Suppl 2:B): 150-5.

52. Norman R J, Mahabeer S, Masters S. Ethnic differences in insulin and glucose response to glucose between white and Indian women with polycystic ovary syndrome. Fertility Sterility 1995; 63: 58-62.

53. Reaven GM, Lithell H, Landsberg L. Hypertension and associated metabolic abnormalities - the role of insulin resistance and the sympathoadrenal system. New England Journal of Medicine 1996; 334: 374-81.

Chandrika N Wijeyaratne, Honorary Research Fellow, Department of Endocrinology, General Infirmary, Leeds, and Senior Lecturer in Reproductive Medicine, Department of Obstetrics and Gynaecology, University of Colombo; Adam H Balen, Consultant Obstetrician and Gynaecologist, and Subspecialist in Reproductive Medicine; and Paul E Belchetz, Consultant Physician and Endocrinologist, General Infirmary, Leeds, U.K. (Revised version received 29 August 2001, accepted 10 November 2001. Corresponding author CNW, E-mail: mandika59@hotmail.com; telephone +941691581 ) 